\title{
A NONLINEAR MATHEMATICAL MODEL FOR DESIGN OPTIMIZATION OF CONSTRUCTION
}

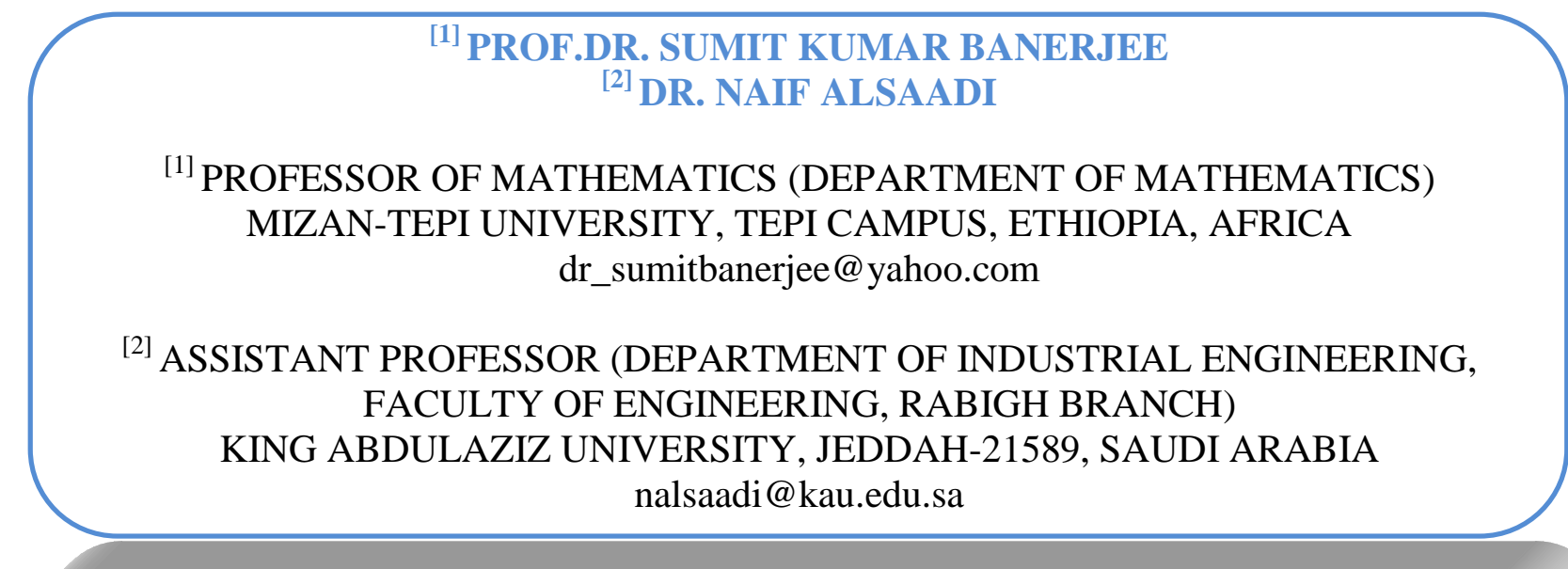

Abstract:

In this research, a nonlinear mathematical model for solving the decision in design construction has been analyzed. The objective of this research is to formulate nonlinear mathematical models to analyze the divisions in constructions and to determine the dimensions of the constructions to have the minimum construction cost. A case study of the condominium building plan is also analyzed.

Key words: Building plan, nonlinear programming, mathematical model, construction

\subsection{Introduction}

Design is the creation of a plan for the construction of an object or a system. This represents a process in which intelligence and creativity are applied to a project to achieve an efficient and elegant solution. Design encompasses functional efficiency, structural integrity, sustainability, lifetime costing, and flexibility as well as responsiveness to the site and its setting. Good design involves creativity and it should lead to simplification and savings in cost. It can increase outputs and add to the quality of service. It can always give the facility a competitive advantage in attracting both customers and staff. Good design can also contribute to wider policy objectives, such as those relating to the protection of the environment. Good designs add value in functionality, reducing whole-life costs, service enhancement, and architectural quality, and wider social and environmental benefits. Generally, the architectural design uses a combination of knowledge both artistic and scientific to create a balance between the functions aesthetics, and economics of buildings. Building plan design is a part of architectural design which uses knowledge. A construction unit cost method that is generally used is the unit cost method which is the value of total output, the value called unit cost. In the construction business, the unit cost is the construction cost per usable area of the building construction. Generally, construction unit cost comes from three parts of cost including materials, labor, and machines. Nonlinear programming technique designed to optimize the usage of limited resources. Successful applications of nonlinear programming exist in the areas of military, industry, agriculture, transportation, economics, health systems, and even behavioral and social sciences. This research problem is to solve decisions in building plan design. First, we divided rooms and dimensions in a building plan of a building 
case study. The differences in construction costs for each part of the buildings affect the total construction cost of the building through different design patterns of the building plan. Thus nonlinear programming model can be used to solve the problem. Outputs of the model were to find out the minimum cost for construction and appropriate usable area in the building within design constraints.

\subsection{Objectives}

- To formulate mathematical models for analysis in dividing rooms and dimensions in a building plan of a building case study.

- To calculate and find out the dimensions and room sizes that have a minimum construction cost

\subsection{Scope of study}

The scope of this research covered analysis and design of a condominium building plan where the mathematical model technique has been applied on comprised of seven rooms. The seven rooms including (i) Dining hall (ii) Kitchen (iii) Toilet (iv) Drawing room (v) Bedroom 1 (vi) Bedroom 2 (vii) Bedroom 3.Construction cost comprised of two parts. Firstly, the construction cost of floors considering unit costs of construction per usable area by classifying functions of each room. Secondly construction cost of walls considering unit costs of construction per wall area by classifying types of external and internal walls. Following Fig. 1 is a bubble diagram that representing relationships between areas in the building plan [1].

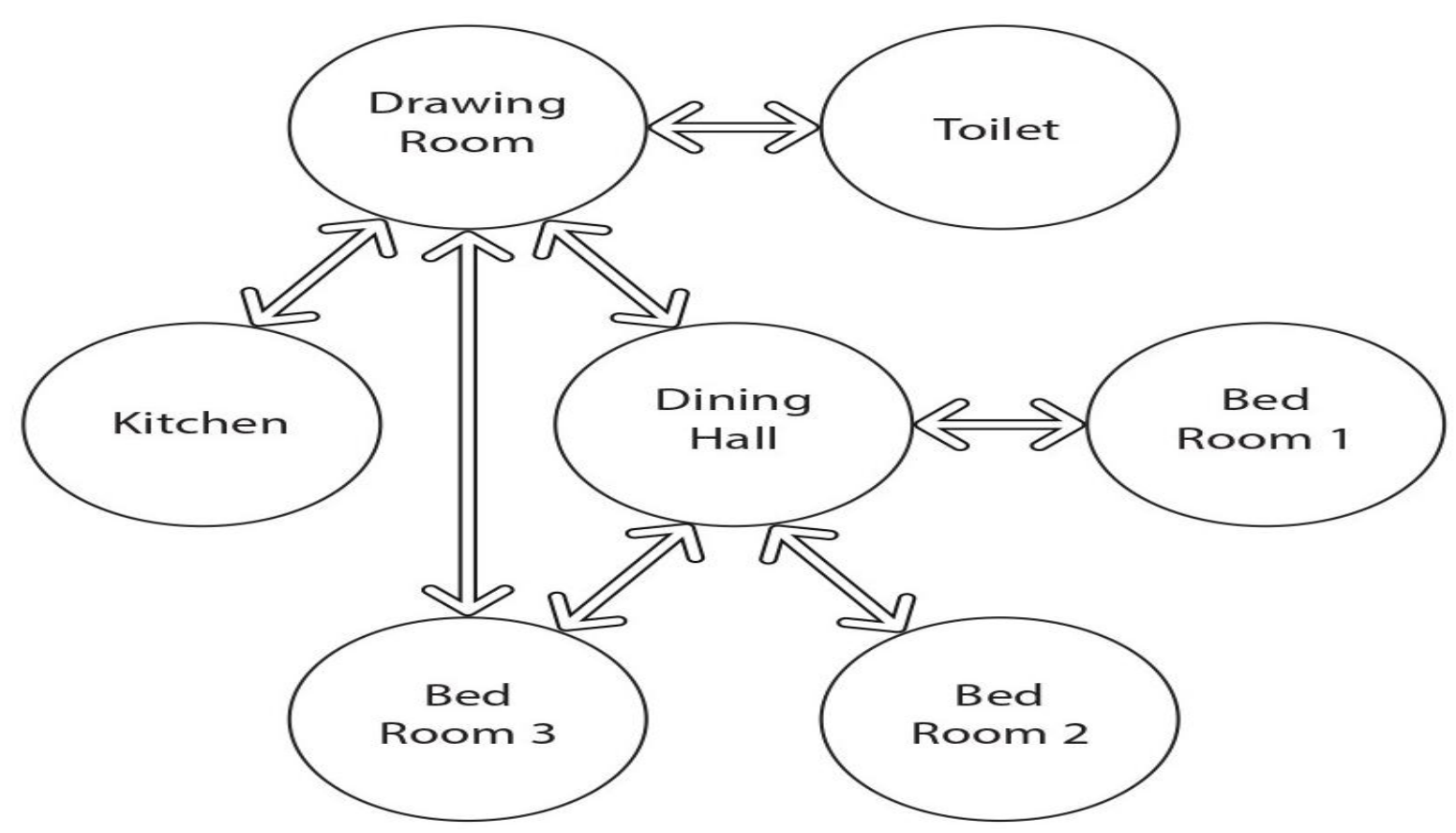

Fig. 1: Relationships between the areas in the building plan

Following Fig. 2 representing the preliminary plan of the building before analysis. 


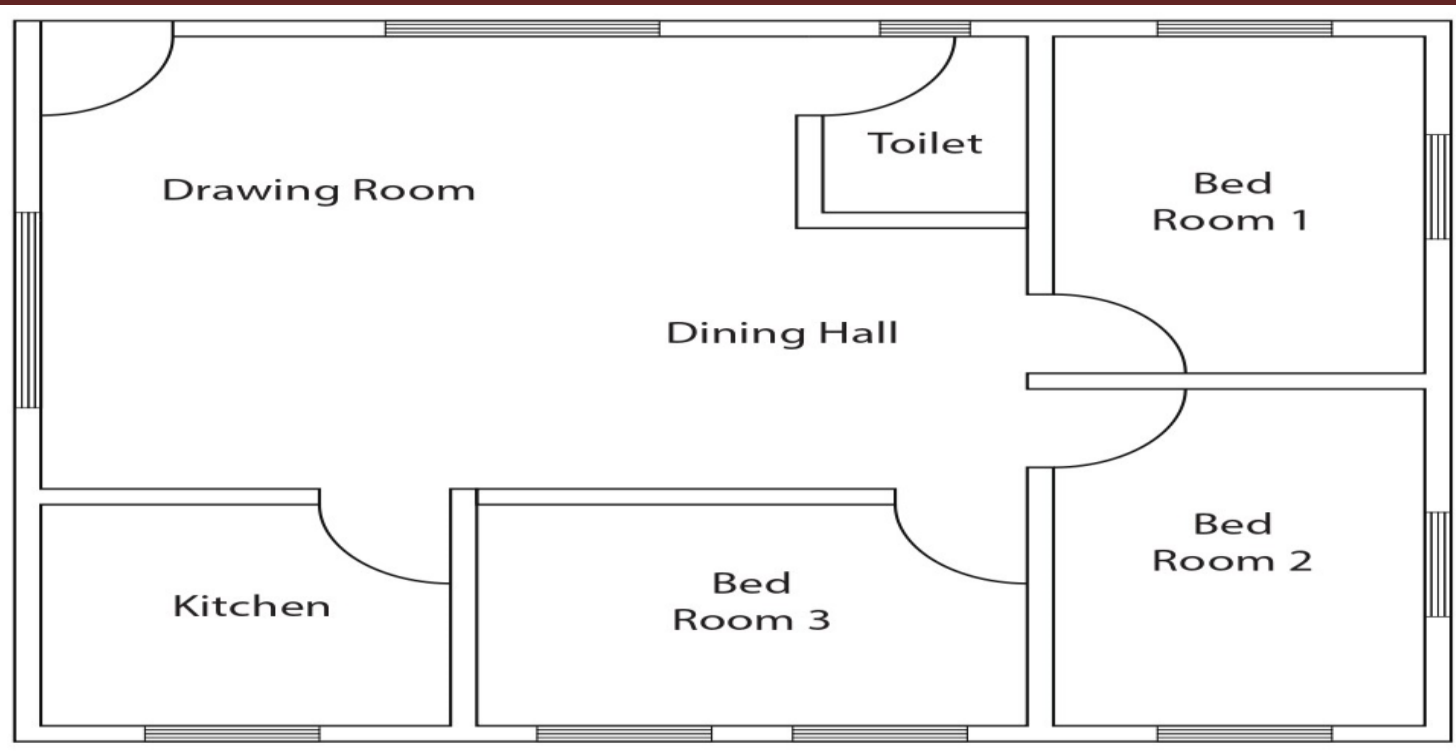

Fig.2: Preliminary plan of the condominium building

\subsection{Literature Review}

Building plan design is a part of architectural design that uses a combination of knowledge both artistic and scientific to create a balance between the functions, aesthetics, and economics of the building. The design process is often described as an orderly arrangement of phases or steps. Yet designers should not think of these steps as having an absolute start and stop points. Not all projects require a designer to go through all the steps, but most benefit from following the process. Each phase is also required thinking critically, working to solve the problem, and making 225 wdecisions to complete the project. The knowledge gained in academic programs provides a foundation for these skills in design. The design process involves numerous activities and tasks to bring about a solution. Some involve working with clients and others involved in the project. As for the design process itself, it has been recognized to involve five phases (as shown in Fig. 3) namely, Design programming, Schematic Design, Design Development, Contract documents and Contract administration.

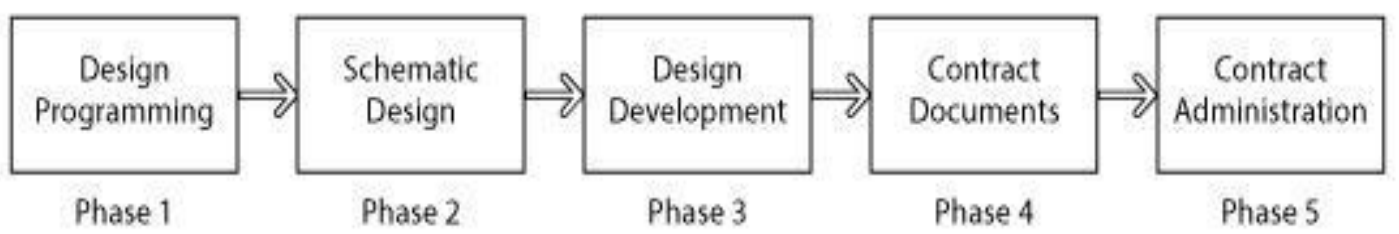

\section{Fig.3: Five phases of the design process}

Design programming is considered the information-gathering phase. The designer seeks to obtain as much information as possible concerning the responsibilities outlined in the scope of services. Depending on the project, information will be gathered from the client, employees, project architect, municipal departments, and others as might be needed.

Schematic design is a design where preliminary planning and early decision-making take place. Bubble diagrams, adjacency diagrams, and concept sketches are common visual documents. Design developments are the stage where the designer finalizes with the client 
many decisions concerning the project. For example, the designer will provide detailed floor plans to ensure that space plans will work and furniture will fit.

Contract documents are the construction and installation drawings, specifications, and required documents needed to get the project built and installed. Dimensioned floor plans, lighting/reflected ceiling plans, and finish schedules represent some of these items.

Contract administration involves the competitive bidding or placing of orders for the work and items to be built and installed. Competitive bidding commonly occurs for commercial projects such as offices. For smaller projects and many residential projects, the designer might be responsible for procuring the goods and services needed to complete the project [2]. In construction cost estimations, Ostward (2001) [3] stated that the unit method is the most convincing of all estimating methods. Examples of unit estimates are found in many business and economic activities such as cost of the house, construction per square foot, cost of electrical transmission per mile, construction cost per hospital bed, chemical plant cost per barrel of oil capacity. The area is perceived to have a powerful effect upon costs and thus its popularity. The the unit method is used extensively such as average material prices, manhours, and labor cost. The unit estimate is defined as the mean where the divisor is the principal cost driver. The rules for calculating the area are:

- All measurements are taken from the internal face of external walls. No deduction is made for internal walls, lift stairwells, etc.

- Where different parts of the building vary in function then the areas are calculated separately.

- External works and non-standard items such as piling are calculated separately and then added to the estimate. Figures for specialist works may be available from sub-contractors and specialist contractors.

\subsection{Linear Programming}

Linear programming is a mathematical modeling technique designed to optimize the usage of limited resources. Successful applications of linear programming exist in the areas of military, industry, agriculture, transportation, economics, health systems, and social sciences [4]. However, not all problems of allocating limited resources can be formulated to fit a linear programming model even as a reasonable approximation. When one or more of the assumptions of linear programming is violated seriously, it may then be possible to apply another mathematical programming model instead of linear programming. E.g. the models of integer programming or nonlinear programming [5]. Many problems are nonlinear in the real world therefore it often is necessary to deal directly with nonlinear programming problems.

Balachandran in 1996 [6] presented an application of multi-criteria optimization which is nonlinear programming in the design of a building plan. Objective functions in the study were to minimize construction cost, maximize usable area and aspect ratio of building area. Constraint functions in the study were requirements of dimensions and room sizes.

\subsection{Nonlinear Programming}

Nonlinear programming is a mathematical model whose objective function and constraint functions are nonlinear. The benefits and applications of nonlinear and linear programming are similar. Presently linear and nonlinear programming software is generally used in personal computers for solving complex problems.

\subsection{Research Methodology}

The research methodology consists of three parts including problem formulation, data collection, and model formulation. 


\subsection{Problem Formulation}

Problems in building plan design were studied and found that the construction cost comprised of two parts. The first part is the construction cost of floors by considering different unit costs of floor constructions for different functions of each room. The second part is the construction costs of walls by considering different unit costs of wall construction for different types of external and internal walls. The differences in construction costs for each part of the building affect the total construction cost of the building through different design patterns of the building plan.

\subsection{Data Collection}

After formulation of the problem data are generally used in the analysis of the problems which researcher took to formulate the mathematical models of nonlinear programming, included the following points:

- From the preliminary plan of the building setting up decision variables into all dimensions in the building plan along the horizontal and vertical axis.

- Collection data regarding owner requirements in dimensions and room sizes of the building plan.

- Collection data regarding building laws and regulations.

\begin{tabular}{|l|l|}
\hline Table 1: Constraints in the condominium building plan design: \\
\hline Rooms & Design constraints \\
\hline Drawing Room & $\begin{array}{l}\text { Owner requirements: Drawing Room } \\
\text { should be at least } 5 m \text { of width and length }\end{array}$ \\
\hline Kitchen & $\begin{array}{l}\text { Owner requirements: Kitchen should be at least } \\
2 m \text { of width and length and at least } 6 m^{2} \text { of area }\end{array}$ \\
\hline Toilet & $\begin{array}{l}\text { Owner requirements: Toilet should be at least } \\
1.5 m \text { of width and length and at least } 3 m^{2} \text { of area }\end{array}$ \\
\hline Dining Hall & $\begin{array}{l}\text { Owner requirements: Size of doors opening to bed } \\
\text { room } 1 \text { and } 2 \text { should be at least } 0.9 m \text { per room } \\
\text { according to the size of the doors. }\end{array}$ \\
\hline Bed Room 1,2,3 & $\begin{array}{l}\text { Owner requirements: Each Bed Room should be at } \\
\text { least } 2.5 m \text { of width and length and at least } 8 m^{2} \text { of } \\
\text { area. All the Bed Rooms should be of same sizes. }\end{array}$ \\
\hline
\end{tabular}

- Collection data regarding unit costs of wall construction for external and internal walls.

- Collection data regarding unit costs of floor construction for each function of the seven rooms.

- Next, construction cost is comprised of two parts. Firstly construction cost of floors considering unit costs of construction per usable area by classifying the functions of each room as shown in table 2. Secondly construction cost of walls considering unit costs of construction per wall area by classifying types of external and internal walls as shown in table 3 . 
Table 2: Unit costs for construction of floor in the condominium building:

\begin{tabular}{|l|l|}
\hline Rooms & Construction cost \\
\hline Drawing room \& Dining hall & $\$ 75 / m^{2}$ \\
\hline Kitchen & $\$ 125 / m^{2}$ \\
\hline Toilet & $\$ 120 / m^{2}$ \\
\hline Bed Room $1,2,3$ & $\$ 70 / m^{2}$ \\
\hline
\end{tabular}

Table 3: Unit costs for construction of walls in the condominium building:

\begin{tabular}{|l|l|}
\hline Walls & Construction cost \\
\hline External Wall & $\$ 65 / \mathrm{m}^{2}$ \\
\hline Internal Wall & $\$ 50 / \mathrm{m}^{2}$ \\
\hline
\end{tabular}

\subsection{Model Formulation}

The formulation of mathematical models in this research is nonlinear programming which comprised of three main parts:

\subsubsection{Decision Variables}

From the preliminary plan of the building, the decision variables are set into all dimensions in the building plan along the horizontal and vertical axis. We have set $X_{1}, X_{2}, X_{3}$ and $X_{4}$ along horizontal axis and $X_{5}, X_{6}, X_{7}$ and $X_{8}$ along vertical axis.

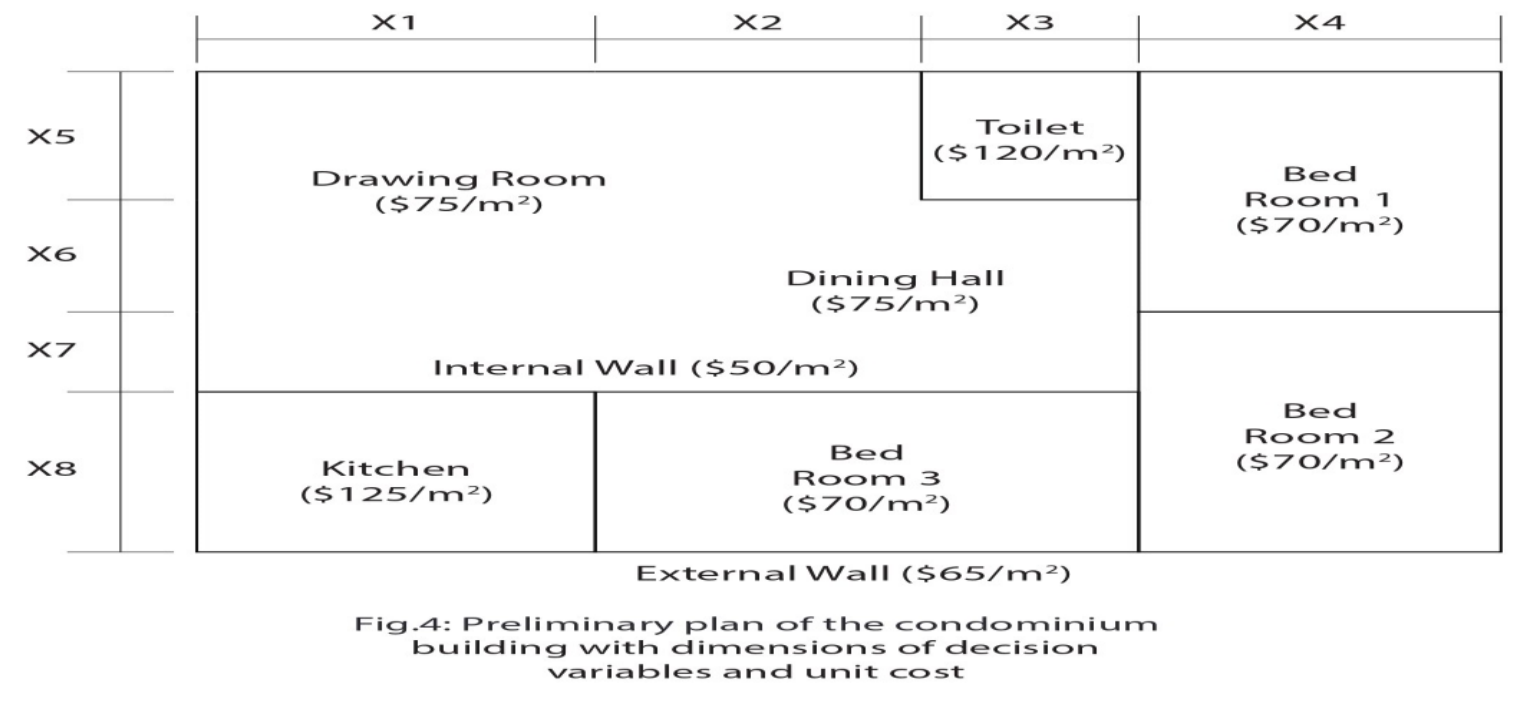




\subsubsection{Objective function}

Objective function of this research minimizing the construction cost.

Minimum cons.cost $=($ Drawing room area $\times$ unit cost of Drawing room $)$

$+($ Dining hall area $\times$ unit cost of Dining hall $)+($ Kitchen area $\times$ unit cost of kitchen $)+$

(Toilet area $\times$ unit cost of Toilet $)+($ Bed Room 1 area $\times$ unit cost of Bed Room 1$)$

$+($ Bed Room 2 area $\times$ unit cost of Bed Room 2$)+($ Bed Room 3 area $\times$ unit cost of Bed Room 3$)$

$+($ total length of external wall $\times$ height of external wall $\times$ unit cost of external wall $)$

$+($ total length of internal wall $\times$ height of internal wall $\times$ unit cost of internal wall $)$

$\Rightarrow$ Minimum cons. cost $=\left(\mathrm{X}_{1}+X_{2}\right) \times\left(X_{5}+X_{6}+X_{7}\right) \times 75+\left(\mathrm{X}_{6}+X_{7}\right) \times X_{3} \times 75+$

$\left(\mathrm{X}_{1} \times X_{8} \times 125\right)+\left(\mathrm{X}_{3} \times X_{5} \times 120\right)+\left(\mathrm{X}_{5}+X_{6}\right) \times X_{4} \times 70+\left(\mathrm{X}_{7}+X_{8}\right) \times X_{4} \times 70$

$+\left(X_{2}+X_{3}\right) \times X_{8} \times 70+\left(X_{1}+X_{2}+X_{3}+X_{4}+X_{5}+X_{6}+X_{7}+X_{8}\right) \times 2 \times 3 \times 65$

$+\left(X_{1}+X_{2}+2 X_{3}+X_{4}+2 X_{5}+X_{6}+X_{7}+2 X_{8}\right) \times 3 \times 50$

$\left[\begin{array}{l}\text { We have considered the height of internal \& external walls as } 3 \text { meters } \\ \text { (Which is the minimum height required for a building) }\end{array}\right]$

\subsubsection{Constraint functions}

Constraint functions included owner requirements:

Drawing Room :

$$
\begin{aligned}
& X_{5}+X_{6}+X_{7} \geq 5 \\
& X_{1}+X_{2} \geq 5
\end{aligned}
$$

Kitchen :

$$
\begin{aligned}
& X_{1} \geq 2 \\
& X_{8} \geq 2 \\
& X_{1} \times X_{8} \geq 6
\end{aligned}
$$

Toilet :

$$
\begin{aligned}
& X_{3} \geq 1.5 \\
& X_{5} \geq 1.5 \\
& X_{3} \times X_{5} \geq 3
\end{aligned}
$$

Dining Hall :

$$
\begin{aligned}
& X_{6} \geq 0.9 \\
& X_{7} \geq 0.9
\end{aligned}
$$

Bed Room 1 :

$$
\begin{aligned}
& X_{4} \geq 2.5 \\
& X_{5}+X_{6} \geq 2.5 \\
& X_{4} \times\left(X_{5}+X_{6}\right) \geq 8
\end{aligned}
$$

Bed Room 2 :

$$
\begin{aligned}
& X_{7}+X_{8} \geq 2.5 \\
& X_{4} \times\left(X_{7}+X_{8}\right) \geq 8
\end{aligned}
$$


Bed Room 3 :

$$
\begin{aligned}
& X_{8} \geq 2.5 \\
& X_{2}+X_{3} \geq 2.5 \\
& X_{8} \times\left(X_{2}+X_{3}\right) \geq 8
\end{aligned}
$$

All the bed rooms should be

of same sizes

Bed Room 1,2,3 :

$$
\begin{aligned}
& X_{4}-X_{8}=0 \\
& X_{2}+X_{3}-X_{5}-X_{6}=0 \\
& X_{5}+X_{6}-X_{7}-X_{8}=0
\end{aligned}
$$

\subsection{Results}

Data analysis has been done by using nonlinear programming software (TORA) for the equations (1) to (22) from the model formulation. Following outputs were obtained.

Table 4: Results analysis by using nonlinear programming software

\begin{tabular}{|l|l|l|l|l|l|l|l|l|l|}
\hline$X_{1}$ & $X_{2}$ & $X_{3}$ & $X_{4}$ & $X_{5}$ & $X_{6}$ & $X_{7}$ & $X_{8}$ & $\begin{array}{l}\text { Construction } \\
\text { cost (in USD) }\end{array}$ & $\begin{array}{l}\text { Usable } \\
\text { area }\left(m^{2}\right)\end{array}$ \\
\hline 2.75 & 2.25 & 1.50 & 2.50 & 2.00 & 1.75 & 1.25 & 2.50 & 15210.62 & 67.50 \\
\hline
\end{tabular}

From the results the preliminary building plan has been drawn according to the output values of $X_{1}$ to $X_{8}$.

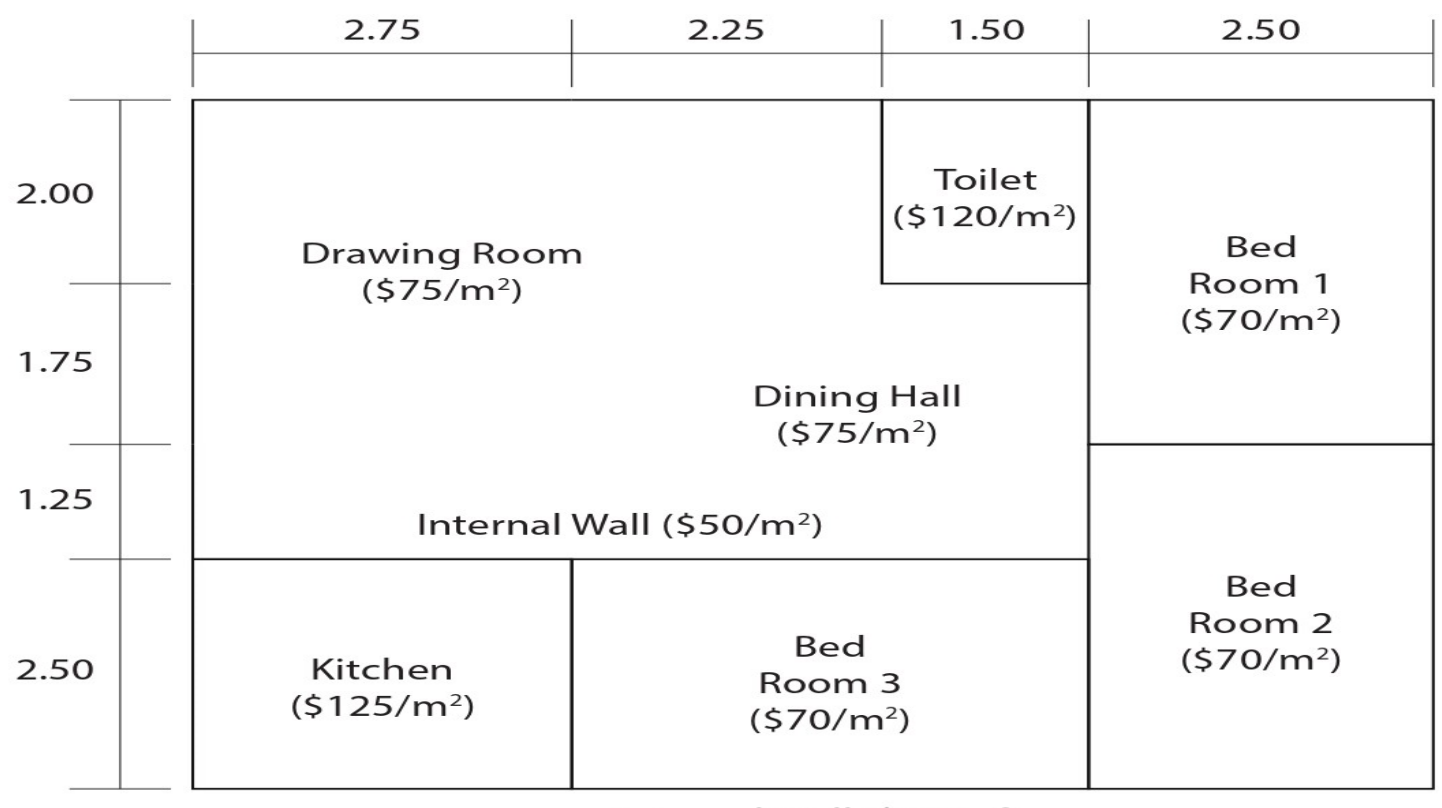

External Wall $\left(\$ 65 / \mathrm{m}^{2}\right)$

Fig.5: Condominium building plan with actual value of decision parameters 


\subsection{Conclusions}

This paper presents a method for solving decision parameters in building plan design by using the mathematical model on nonlinear programming. Outputs of the model were to find out the minimum cost for construction and appropriate usable area in the building within design constraints such as owner's requirements in room sizes, building laws and regulations, construction costs of the floor for each room, and external and internal walls by using the unit cost method in construction estimation. A case study of the condominium building plan is analyzed and calculated in this research. By using this model an architect will be able to choose the best solution based on the construction cost aspect. This mathematical model can be applied in other more complicated building plans such as a part of the circular building plan, triangular building plan, or other geometrical shaped building plans. Moreover, the constraint functions can be added more other requirements such as required room sizes for furniture sizes or other conditions. The applications of this mathematical model can also be applied to other objective functions such as maximize the usable area in the building within the construction cost budget. The objective function can also be set for multi-criteria optimizations such as minimizing the construction cost, maximized usable area, and aspect ratio of building area.

\section{References}

[1] Hershberger, Robert G. (1999), Architectural programming and pre-design Manager, McGraw-Hill publication, New York, PP. 49-54.

[2] Piotrowski, Christine M. (2011), Problem-solving and critical thinking for a designer, John Wiley \& Sons, Hoboken, New Jersey, PP. 14-16.

[3] Ostwald F. Phillip (2016), Construction cost analysis and estimating, Prentice-Hall International, New Jersey, PP. 195-197.

[4] Taha Hamdy A. (1997), Operations Research an Introduction, Prentice-Hall International, New Jersey.

[5] Hillier s. Frederick and Lieberman J. Gerald (1990), Introduction to Operations Research, 5th ed., McGraw-Hill Book co.

[6] Balachandran M. (1996), Knowledge-based optimum design, computations Mechanics publication, Boston, USA, PP. 35-49. 